\title{
Species differences in the pattern of eicosanoids produced by inflamed and non-inflamed tissue
}

\author{
F. J. Zijlstra ${ }^{1}$, A. P. M. van Dijk ${ }^{1}$, I. M. Garrelds ${ }^{1}$, R. J. T. Ouwendijk ${ }^{3}$ and J. H. P. Wilson ${ }^{2}$ \\ ${ }^{1}$ Department of Pharmacology and ${ }^{2}$ Department of Internal Medicine II, Erasmus University and ${ }^{3}$ Department of Internal \\ Medicine, Ikazia Hospital, P.O. Box 1738, 3000 DR Rotterdam, The Netherlands
}

\begin{abstract}
The synthesis of ${ }^{14} \mathrm{C}$ labelled arachidonic acid metabolites was measured in colonic tissues obtained from mice, rats, guinea pigs, rabbits, piglets and in colonic biopsies from humans during colonoscopy. The main eicosanoids formed after stimulation with calcium ionophore A23187 were: in humans, 15-hydroxyeicosatetraenoic acid (15-HETE); in mice, 12-HETE; in rats, 12-HETE, 12-hydroxy- 5,8,10-heptadecatrienoic acid (HHT) and 6-keto-prostaglandine $\mathrm{F}_{1 \alpha}\left(6 \mathrm{kPGF}_{1 \alpha}\right)$; in guinea pigs, $\mathrm{PGD}_{2}$; in rabbits, $6 \mathrm{kPGF}_{1 \alpha}$, $\mathrm{PGE}_{2}$ and 15-HETE; and in pigs $\mathrm{PGE}_{2}$ and 12-HETE. In inflamed 15-HETE production was increased in man, HHT and 12-HETE production in rats and overall eicosanoid production in mice.
\end{abstract}

\section{Introduction}

Several experimental models have been described which resemble idiopathic human inflammatory bowel disease (ulcerative colitis and Crohn's disease), and these animal models have been used to study the biochemistry of intestinal mucosal inflammation and the effects of various forms of treatment [1]. The usual treatments of idiopathic inflammatory bowel disease - corticosteroids and 5-aminosalicylates - are thought to act by interfering with eicosanoid production. In recent years more specific blockers of arachidonate metabolites have become available, and these are of potential interest in the treatment of inflammatory bowel disease. It would greatly aid the development of new treatments if there would be an animal model which was very similar to human inflammatory bowel disease, not only histologically but also in the pattern of eicosanoids produced in the inflamed mucosa.
In the search for a suitable animal model for ulcerative colitis (UC), we compared the pattern of arachidonate metabolites produced by the colonic mucosa of 5 animal species with that of man. In this study we examined eicosanoid production patterns in normal mucosa and in inflamed mucosa.

\section{Methods}

Normal colonic mucosa was obtained from $8 \mathrm{BALB} / \mathrm{c}$ mice (female), $6 \mathrm{Wistar}$ rats (male), $5 \mathrm{NZW}$ rabbits (male), 5 albino guinea pigs (female) and 5 Dutch piglets (female) immediately after sacrificing the animals, and biopsies were taken from humans during colonoscopy. In this study 13 patients ( 6 men, 7 women) from whom any kind of inflammatory bowel disease was excluded (in most patients the colonoscopy was performed as a follow up 1-2 years after polypectomy) were considered as controls and in addition 11 patients 
Table 1

Eicosanoid production by colonic tissue from humans, rats and mice (expressed as dpm per $100 \mathrm{mg}$ tissue).

\begin{tabular}{|c|c|c|c|c|c|c|}
\hline \multirow{3}{*}{$\mathrm{GkPGF}_{1 \alpha}$} & \multirow{2}{*}{\multicolumn{2}{|c|}{$\begin{array}{l}\text { HUMANS } \\
\text { contr. inflamm. }\end{array}$}} & \multirow{2}{*}{\multicolumn{2}{|c|}{ ontr. RATS }} & \multicolumn{2}{|c|}{ MICE } \\
\hline & & & & & contr. & inflamm. \\
\hline & $450 \pm 80$ & $270 \pm 40$ & $2850 \pm 510$ & $3450 \pm 1240$ & $340 \pm 70$ & $1820 \pm 210$ \\
\hline $\mathrm{PGF}_{2 \alpha}$ & $670 \pm 80$ & $530 \pm 60$ & $250 \pm 50$ & $340 \pm 110$ & $140 \pm 30$ & $1020 \pm 160$ \\
\hline $\mathrm{PGE}_{2}$ & $810 \pm 110$ & $610 \pm 80$ & $450 \pm 190$ & $530 \pm 280$ & $220 \pm 30$ & $1230 \pm 180$ \\
\hline $\mathrm{PGD}_{2}$ & $450 \pm 90$ & $450 \pm 100$ & $510 \pm 150$ & $240 \pm$ & $230 \pm 50$ & $1330 \pm 160$ \\
\hline HHT & $1170 \pm 230$ & $1200 \pm 120$ & $1230 \pm 300$ & $2530 \pm 200$ & $230 \pm 30$ & $1020 \pm 130$ \\
\hline $\mathrm{LTB}_{4}$ & $250 \pm 40$ & $230 \pm 40$ & $610 \pm 130$ & $960 \pm 180$ & $\leq 30$ & $320 \pm 40$ \\
\hline di-HETE & $440 \pm 70$ & $290 \pm 40$ & $390 \pm 90$ & $430 \pm \quad 30$ & $\leq 30$ & $250 \pm 20$ \\
\hline 5-HETE & $\leq 30$ & $\leq 30$ & $\leq 30$ & $\leq 30$ & $\leq \mathbf{3 0}$ & $350 \pm 50$ \\
\hline 12-HETE & $360 \pm 40$ & $570 \pm 70$ & $1610 \pm 160$ & $4610 \pm 1220$ & $480 \pm 110$ & $1860 \pm 230$ \\
\hline 15-HETE & $2470 \pm 260$ & $3690 \pm 390$ & $270 \pm 60$ & $340 \pm$ & $130 \pm 20$ & $980 \pm 180$ \\
\hline
\end{tabular}

( 8 men, 3 women) with a non-treated UC were examined as examples of inflammatory bowel disease.

Experimental colitis in rats was induced by injection of $2 \mathrm{ml}$ of $5 \%$ acetic acid into the lumen of the colon. Twenty-four hours later the animals were killed and the colons removed [2]. Colitis in mice was induced by the addition of dextran sulphate sodium to the drinking water, $10 \%(\mathrm{w} / \mathrm{v})$ ad libitum [3].

Tissue samples were homogenised in Krebs buffer, incubated for $10 \mathrm{~min}$ with $0.125 \mu \mathrm{Ci}{ }^{14} \mathrm{C}$-arachidonic acid (Amersham, UK) and stimulated with Ca-ionophore A23187 $(1 \mu M)$. The radiolabelled eicosanoids formed were separated by HPLC and measured by on-line beta detection [4].

\section{Results}

In the comparison of non-inflamed tissues obtained from six different species, including man, the following was observed. The main eicosanoids formed are: in humans, 15-HETE; in mice, 12-HETE; in rats, 12-HETE, HHT and $6 \mathrm{kPGF}_{1 \alpha}$; in guinea pigs, $\mathrm{PGD}_{2}$, diHETE and a number of unidentified metabolites; in rabbits, $6 \mathrm{kPGF}_{1 \alpha}, \mathrm{PGE}_{2}$ and 15HETE; and in pigs, $\mathrm{PGE}_{2}$ and 12-HETE. LTB $_{4}$ in humans was present in the lowest amounts and was barely detectable in the other 5 species.

Eicosanoid production by inflamed colonic tissue was increased in the three models used (Table 1).
In man, a $50 \%$ increase was observed in 12 - and 15-HETE formation. In rats, mainly HHT and 12-HETE production was markedly increased. In mice, the overall eicosanoid formation was increased 5-fold.

\section{Discussion}

In previous studies we have shown that there are marked species and site differences in the production pattern of eicosanoids by inflammatory cells [5]. The present study, in which tissue homogenates were used, again illustrates the species differences in inflammatory mediator production. While this probably has little implication for study of the effects of less specific anti-inflammatory agents such as 5-aminosalicylate, which have a diffuse suppressive action on eicosanoid formation, it is probably important while designing studies of specific receptor blockers or specific enzyme blockers as potential drugs for human inflammatory bowel disease.

\section{Conclusions}

There are marked species differences in eicosanoid production by inflamed and non-inflamed colonic mucosa. These differences should be taken into account while comparing animal models with human inflammatory bowel disease. 


\section{References}

[1] W. L. Beeken, Experimental inflammatory bowel disease. In Inflammatory Bowel Disease, 3rd edition (Eds. J. B. Kirsner and R. G. Shorter) pp. 37-49, Lea \& Febiger, Philadelphia 1988.

[2] P. Sharon and W. F. Stenson, Enhanced synthesis of leukotriene $B_{4}$ by colonic mucosa in inflammatory bowel disease. Gastroenterology 86, 453-460 (1984).

[3] I. Okayasu, S. Hatakeyama, M. Yamada, T. Ohkusa, Y. Inagaki and R. Nakaya, A novel method in the induction of reliable experimental acute and chronic ulcerative colitis in mice. Gastroenterology 98, 694-702 (1990).

[4] F. J. Zijlstra, J. H. P. Wilson, M. A. Vermeer, R. J. Th. Ouwendijk and J. E. Vincent, Differential effects of malotilate on 5-, 12-, and 15-lipoxygenase in human ascites cells. Eur. J. Pharmacol. 159, 291-295 (1989).

[5] R. J. Th. Ouwendijk, F. J. Zijlstra, A. M. W. C. vd Broek, A. Brouwer, J. H. P. Wilson and J. E. Vincent, Comparison of the production of eicosanoids by human and rat peritoneal macrophages and rat kupffer cells. Prostaglandins 35 . 437-446 (1988). 